\title{
Effects of supernumerary heterochromatin on chiasma formation and chromosome segregation in Dociostaurus genei (Orthoptera)
}

\author{
E. RODRÍGUEZ ÍNIIGO†, P. L. MASON, J . S. RUFAS \& C. GARCÍA DE LA VEGA* \\ Departamento de Biología, Facultad de Ciencias, Universidad Autónoma de Madrid, E-28049 Madrid, Spain
}

\begin{abstract}
Dociostaurus genei is a grasshopper in which most of the autosomes present polymorphisms for distal heterochromatic supernumerary segments. C-banding, DAPI banding and fluorescence in situ hybridization (FISH) of a probe, which is representative of the highly repetitive DNA sequences comprising the segments, have been used to analyse the effects of the segments on chiasma formation. Results show that the supernumerary segments are associated with two major effects. First, a higher content of supernumerary heterochromatin is correlated with the formation of a lower number of chiasmata within a given chromosome complement. Secondly, because the methods used strongly suggest that the distal segments are truly terminal, they could be considered to be involved in the maintenance of achiasmate associations that persist up to the first anaphase migration. These terminal associations occurred in about 50 per cent of homozygous and heterozygous bivalents and did not impair the correct segregation of homologues at anaphase I.
\end{abstract}

Keywords: chiasma formation, heterochromatin, meiosis, Orthoptera, terminal associations.

\section{Introduction}

A supernumerary segment is a portion of heterochromatin that is amplified and clearly dispensable (John, 1983). In many orthopteroid insects, they are polymorphic and usually occupy distal positions in the smaller members of a given chromosome complement (Hewitt, 1979). In some cases, most of the autosomes possess this kind of extra material (see, for example, John \& King, 1983). Although they are usually heterochromatic, i.e. they stain positively after C-banding, a very few cases of 'euchromatic' extra segments have been reported (Camacho et al., 1984; García de la Vega et al., 1986; Suja et al., 1994). Molecular analysis has shown them to be composed mainly of particular families of highly repetitive DNA (John et al., 1986; Rodríguez Iñigo et al., 1996).

Possible effects of supernumerary segments on chiasma formation have been analysed frequently.

$\dagger$ Present address: Unidad de Hepatología, Fundación Jiménez Díaz y Fundación para el Estudio de las Hepatitis Virales, 28040 Madrid, Spain.

*Correspondence. E-mail: carlos.delavega@uam.es.
Most commonly, the presence of supernumerary segments is correlated with an increase in mean chiasma frequency, although cases in which a lack of any such relation or, more rarely, in which there is a decrease in mean chiasma frequency have been reported (Hewitt, 1979). Moreover, males and females may not be influenced to the same extent (Santos, 1993). The influence of supernumerary segments on chiasma distribution within the affected bivalent has also been studied extensively (Suja et al., 1994). Chiasmata usually form well away from the segment, although the behaviour of bivalents heterozygous or homozygous for the presence of a segment may differ (De la Torre et al., 1986).

Wolf (1994) has recently reviewed different modes by which achiasmate chromosomes may associate, including the 'stickiness' of heterochromatic regions. In the case of distal supernumerary segments, this behaviour would lead to terminal associations that could be observed in diplotene and persist up to the first anaphase migration (Hewitt, 1979; John \& King, 1985). However, whether they are truly achiasmate or not is still a matter of debate (Jones, 1987; Wada \& Imai, 1995). 
Dociostaurus genei is a grasshopper in which distal supernumerary segments can occur in eight of its 11 autosome pairs (Rodríguez Iñigo et al., 1993). The segments are homogeneous and mainly composed of a highly repetitive AT-rich DNA sequence (Rodríguez Iñigo et al., 1996). The aim of this paper is to analyse the influence of this extra material on chiasma formation and its involvement in bivalent maintenance throughout the first meiotic division.

\section{Material and methods}

Adult male and female Dociostaurus genei were collected from natural populations near Madrid, Spain. The karyotype of males consists of 11 acrocentric autosome pairs and a single acrocentric sex (X) chromosome. The autosomes are arranged into three groups according to their size: large (L1-L3), medium (M4-M8) and short (S9-S11). The sex chromosome determinism is of the $\mathrm{X} 0$ (male), $\mathrm{XX}$ (female) type.

Fixation of testes and ovarioles was carried out in 3:1 ethanol-acetic acid. Before being dissected, females were injected intra-abdominally with 0.05 per cent colchicine in insect saline solution and left for $5 \mathrm{~h}$. Squash preparations were made in a drop of 45 per cent acetic acid. The coverslips were removed after freezing in liquid nitrogen, and the slides were then air dried. C-banding was performed according to López-Fernández \& Gosálvez (1981). The protocols for fluorescence banding with 4,6-diamidino2-phenylindole (DAPI) and fluorescence in situ hybridization (FISH) have been described elsewhere (Rodríguez Iñigo et al., 1993, 1996). EMBL accession numbers of the probes used are X83723 and X83724 for DgA3 and DgT2 sequences, respectively.
Between seven and 12 C-banded diplotene cells from 34 individuals were analysed to determine chiasma frequency. After a preliminary inspection of the data, bootstrap regressions of chiasma frequency on the number of chromosome pairs lacking supernumerary blocks (BB bivalents) were performed.

The frequency of terminal associations (end-toend contacts) was scored in C-banded metaphase I plates from 21 individuals whose bivalents were heterozygous $(\mathrm{BH})$ or homozygous $(\mathrm{HH})$ for the presence of a distal segment.

\section{Results}

\section{Chiasma frequency}

The C-banding pattern of $D$. genei consists of large procentric blocks present in every chromosome and distal supernumerary segments (Figs 1 and 2f). The latter can be found in up to 8 of the 11 autosome pairs, although they never occur in the three longest pairs (L1-L3) or the sex (X) chromosome. If all medium-sized and short chromosome pairs can be polymorphic, then there would be $6561\left(3^{8}\right)$ possible karyomorphs. It would clearly be impractical to analyse adequate numbers of each karyomorph in a given population, so we have classified the 34 individuals studied according to the number of autosome pairs that lacked supernumerary segments (BB bivalents). Therefore, we have not discriminated between bivalents heterozygous $(\mathrm{BH})$ or homozygous $(\mathrm{HH})$ for the presence of supernumerary segments. Table 1 summarizes the data with respect to the chiasma frequencies, scored in C-banded diplotenes, in the entire karyotype and in the three longest chromosome pairs (L1-L3) for each karyomorph group. In this analysis, end-to-end contacts

Table 1 Summary statistics of numbers of chiasmata observed in the entire karyotype of Dociostaurus genei and solely in the three long chromosomes (L1-L3) for individuals with different numbers of chromosome pairs lacking supernumerary heterochromatic blocks

\begin{tabular}{|c|c|c|c|c|c|c|}
\hline \multirow{3}{*}{$\begin{array}{l}\text { Number of chromosome } \\
\text { pairs lacking } \\
\text { heterochromatic } \\
\text { blocks }\end{array}$} & \multirow{3}{*}{$\begin{array}{l}\text { Number of } \\
\text { individuals }\end{array}$} & \multirow{3}{*}{$\begin{array}{c}\text { Number } \\
\text { of cells }\end{array}$} & \\
\hline & & & \multicolumn{2}{|c|}{ Whole karyotype } & \multicolumn{2}{|c|}{ Chromosomes L1-L3 } \\
\hline & & & Mean & Variance & Mean & Variance \\
\hline $3 \mathrm{BB}$ & 1 & 9 & 14.56 & 0.527 & 6.11 & 0.361 \\
\hline $4 \mathrm{BB}$ & 8 & 68 & 14.77 & 1.227 & 6.00 & 0.209 \\
\hline $5 \mathrm{BB}$ & 15 & 126 & 15.49 & 1.658 & 6.21 & 0.314 \\
\hline $6 \mathrm{BB}$ & 8 & 70 & 16.07 & 4.705 & 6.56 & 0.917 \\
\hline $7 \mathrm{BB}$ & 1 & 12 & 19.25 & 1.476 & 7.83 & 0.697 \\
\hline $8 B B$ & 1 & 8 & 19.38 & 2.268 & 8.50 & 0.286 \\
\hline
\end{tabular}


involving heterochromatic blocks were scored as chiasmata. Particularly in HH bivalents, it is difficult to ascertain whether the contacts are attributable to the procentric or the distal blocks at that meiotic stage (Fig. 1b).

In the absence of any constraints on chiasma formation, observed chiasma frequencies might be expected to follow a Poisson distribution (Jones, 1984). A preliminary examination of the data did not suggest this to be the case in any of the different karyomorph groups: means were greater than the associated variances (they would have been the same were the data Poisson distributed; Table 1), implying that chiasma formation was constrained. Further analysis of this relationship can be carried out using methods that make no assumption about the underlying distribution. To this end, bootstrap regression of chiasma frequencies on the number of chromosome pairs lacking supernumerary blocks was carried out by resampling the data with replacement 1000 times, calculating the regression statistics for each resampled data set and then calculating their means and 95 per cent confidence intervals. Regression estimates are significant if the range of the confidence interval does not span zero. Separate analyses were performed on the data of the entire karyotype and of those solely from chromosomes L1-L3 (Table 2). There was a significant decrease in the chiasma frequency of 0.977 in the entire chromosome complement for each unitary increase in the number of supernumerary segments. Chromosome pairs L1-L3 themselves never showed extra segments, but there was a smaller but also significant interchromosomal effect, whereby the chiasma frequency decreased by 0.442 in these autosomes for a unitary increase in the number of supernumerary segments in the entire karyotype (Table 2).

\section{Terminal associations}

We have not analysed the possible effects of distal segments on chiasma distribution because the presence of distal blocks in the majority of the autosomes makes it impractical to discriminate individual bivalents. Moreover, most of the smaller members of the complement (S9-S11 bivalents) proved to be homozygous for the presence of supernumerary segments and, because C-banding does not discriminate between procentric and supernumerary heterochromatin, it was very difficult to ascertain the position of single chiasmata (Fig. 1b). Nonetheless, as mentioned above, some diplotene bivalents exhibited a single end-to-end contact involving heterochromatic blocks. The analysis of C-banded metaphase I plates in which bivalents were bipolarly orientated (Fig. 1a) proved useful in determining whether the associations involved either the procentric or the distal heterochromatic blocks and the frequency of such associations. We studied 21 individuals in which medium-sized and short chromosome pairs (M5-S11) were either heterozygous or homozygous for the presence of supernumerary segments. In every case, the end-to-end contacts involved only the distal segments (Fig. 1a), indicating that the terminal associations of homologues of $\mathrm{HH}$ bivalents observed in diplotene are not proximal chiasmata located on the short arms. Table 3 shows that such associations are not uncommon in either $\mathrm{BH}$ or $\mathrm{HH}$ bivalents. More than 50 per cent of $\mathrm{HH}$ bivalents showed persistent heterochromatinheterochromatin associations, whereas some 30 per cent of the scored BH bivalents showed euchromatin-heterochromatin associations (Fig. 1). These latter would have given rise to reductional separations at anaphase I. Within the limits of the resolving power of C-banding (Fig. 1d) and DAPI banding (Fig. 2c), some anaphase I half-bivalents showed this mode of segregation.

If terminal associations were achiasmate connections between homologues maintained by distal heterochromatic blocks (John \& King, 1985), then this would imply that the supernumerary segments should occupy truly distal positions. In our case, the banding methods used did not reveal any visible euchromatin region beyond the segment in mitotic chromosomes (Fig. 2f; Rodríguez Iñigo et al., 1993). However, some HH bivalents at metaphase I show a region between both homologues that is not positive to C-banding (Fig. 1a) and that could be considered to be a euchromatin region. We have used FISH to examine this in greater detail. Two families of highly repetitive DNA of $D$. genei have been characterized elsewhere (Rodríguez Iñigo et al., 1996). One of them (DgT2) is localized exclusively in the centromeric heterochromatin of each chromosome (Rodríguez Iñigo et al., 1996). It is noteworthy that in this case a presumed short arm located above the procentric heterochromatin is clearly visible in mitotic and meiotic chromosomes (Fig. 2a and d). The other family (DgA3) represents the major component of the supernumerary segments. The DgA3 probe hybridized exclusively to the region at which the supernumerary segments were located (Rodríguez Iñigo et al., 1996), and no euchromatin tip was ever observed beyond the segment in either mitotic or meiotic chromosomes (Fig. $2 b$ and e). Furthermore, when terminal associations occurred, they seemed to be sustained by the interaction of 


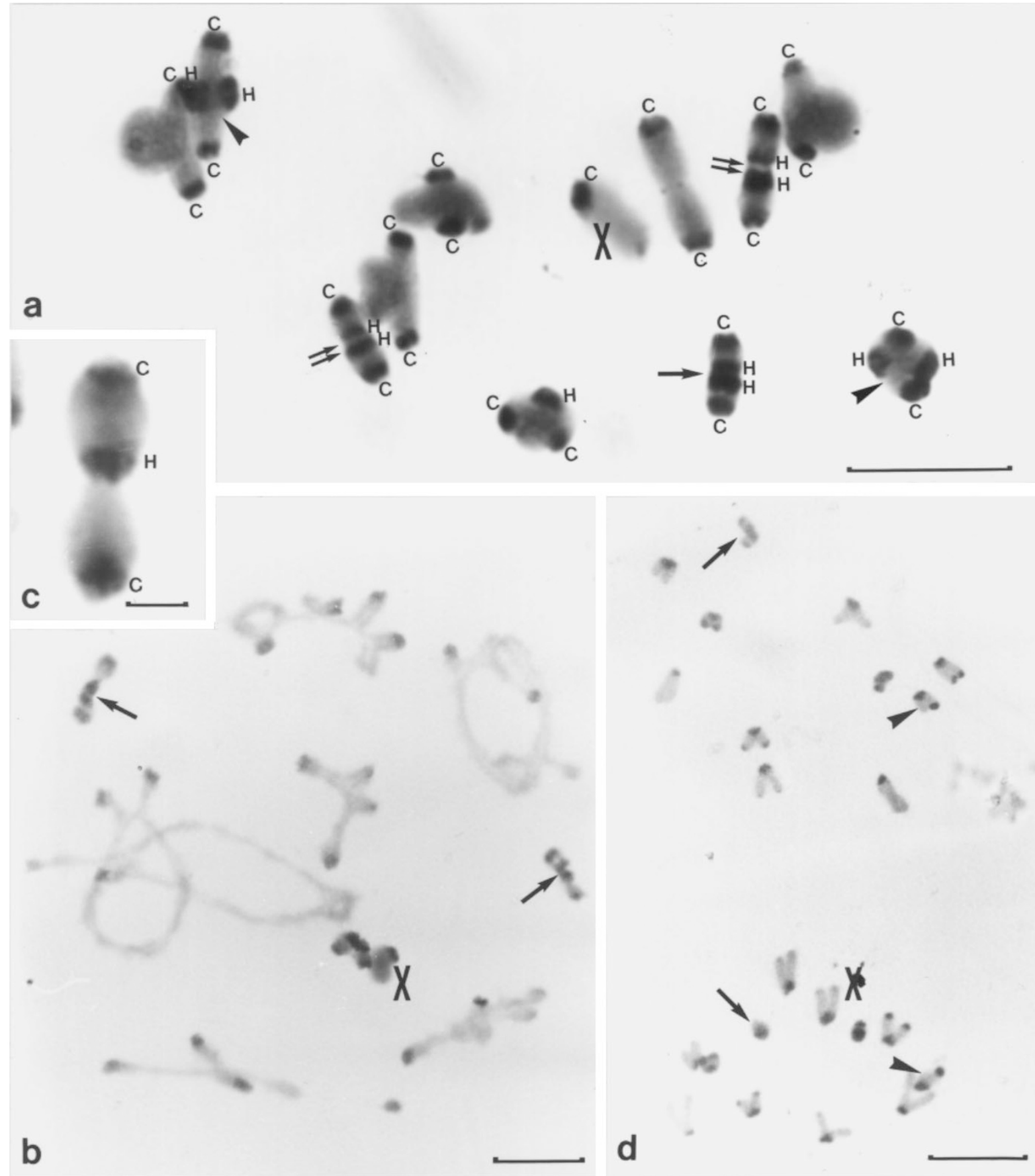

Fig. 1 C-banded spermatocytes of Dociostaurus genei. (a) Metaphase I showing the 11 autosome bivalents and the sex (X) chromosome. Every chromosome shows large procentric heterochromatic blocks (C) and some of the autosomes show distal supernumerary segments $(\mathrm{H})$. The bipolar orientation of the bivalents allows it to be discerned whether homologues of HH bivalents are held together by a chiasma (arrowheads) or a terminal association (arrows). Notice that, in two $\mathrm{HH}$ bivalents, a presumed euchromatic region can be seen between both supernumerary segments (double arrows). (b) Diplotene showing two HH small bivalents (arrows) held together at one of the chromosome ends by heterochromatin. C-banding does not discriminate between heterochromatin located near the centromere and that located at the distal end. $\mathrm{X}$, sex chromosome. (c) Selected BH bivalent at the onset of anaphase I showing a terminal association between homologues. This configuration may lead to a reductional separation as observed in (d) and Fig. 2c. (d) Anaphase I showing half-bivalents after equational (arrowheads) and reductional (arrows) separations of BH bivalents. X, sex chromosome. In a, c and d, bars represent $10 \mu \mathrm{m}$. In b, bar represents $2 \mu \mathrm{m}$. 
Table 2 Bootstrap statistics and 95 per cent confidence intervals for regression of chiasma frequency on numbers of chromosome pairs lacking supernumerary heterochromatic blocks in Dociostaurus genei

\begin{tabular}{lcccc}
\hline Comparison & $\begin{array}{c}\text { Regression } \\
\text { coefficient }\end{array}$ & $\begin{array}{c}95 \text { per cent } \\
\text { confidence interval }\end{array}$ & Constant & $\begin{array}{c}95 \text { per cent } \\
\text { confidence interval }\end{array}$ \\
\hline Entire karyotype & -0.977 & $-1.161,-0.790$ & 10.702 & $9.839,11.597$ \\
Chromosomes L1-L3 & -0.442 & $-0.539,-0.339$ & 4.113 & $3.638,4.612$ \\
\hline
\end{tabular}

Values are provided for the entire karyotype and for the three longest chromosomes (L1-L3), which themselves were never observed to possess supernumerary segments.

the distal segments themselves. This became particularly evident when chromosomes were stretched (Fig. 2b).

\section{Discussion}

Our results show that the presence of supernumerary segments in $D$. genei is correlated with intra- and interchromosomal decreases in chiasma frequency (Tables 1 and 2). This result is unusual because supernumerary segments that are polymorphic in a single chromosome pair are most commonly associated with an increase in the frequency of chiasmata (Hewitt, 1979). It is probable that a single chiasma formed within some of the medium $\mathrm{BH}$ and $\mathrm{HH}$ chromosome pairs, in which two chiasmata might otherwise have occurred when the segments were absent. There was also an interchromosomal effect on the three longest pairs, which significantly reduced the number of chiasmata formed in the karyomorphs with the highest content of extra heterochromatin (classes 3BB and 4BB).

The conclusion of the influence of supernumerary segments on the pattern of chiasma formation in $D$. genei is reinforced by the analysis of the pattern of chiasmata formation in the $\mathrm{BH}$ and $\mathrm{HH}$ bivalents. The presence of a supernumerary segment is most commonly correlated with the displacement of the chiasmata away from the position of the extra segment (Santos et al., 1993; Suja et al., 1994). Although we have not carried out a similar analysis, our data show that terminal associations are quite frequent in $\mathrm{HH}$ and $\mathrm{BH}$ bivalents (Table 3). If these associations were truly achiasmate, then the results presented in Table 3 would imply that the pattern of chiasma formation had been biased in two ways. First, a substantial number of $\mathrm{BH}$ and $\mathrm{HH}$ bivalents would have had their chiasmata replaced by terminal associations involving supernumerary heterochromatin. Secondly, because, in scoring chiasma frequency, any bound arms observed in diplotene cells were considered to be maintained by a chiasma, the effect of supernumerary segments on the frequency of chiasmata (Tables 1 and 2) would have been underestimated.

The nature of terminal associations, in which heterochromatin is involved, is embroiled in controversy with opinions falling into two main camps. One of these deems terminal associations to represent true chiasmata (Jones \& Tease, 1984; Jones, 1987; Latos-Bielenska \& Vogel, 1990; Santos \& Esteban, 1990), whereas the other considers that they are achiasmate contacts (John \& King, 1985; Wada \& Imai, 1995; Benavente et al., 1996).

There are two differing explanations, which assume that terminal associations involving hetero-

Table 3 Percentages of chiasmata and terminal associations (TA) in 21 individual Dociostaurus genei with bivalents heterozygous $(\mathrm{BH})$ and homozygous (HH) for the presence of supernumerary segments $(n=$ number analysed $)$

\begin{tabular}{|c|c|c|c|c|c|c|}
\hline \multirow{2}{*}{$\begin{array}{l}\text { Chromosome } \\
\text { pairs }\end{array}$} & \multicolumn{3}{|c|}{ Heterozygous bivalents } & \multicolumn{3}{|c|}{ Homozygous bivalents } \\
\hline & Chiasmata & TA & $n$ & Chiasmata & TA & $n$ \\
\hline M5-S9 & 65.6 & 34.4 & 241 & 43.3 & 56.7 & 506 \\
\hline S10-S11 & - & - & & 48.3 & 51.7 & 323 \\
\hline
\end{tabular}

The sample is divided into two groups: M5-S9 chromosome pairs, which are $\mathrm{BH}$ or $\mathrm{HH}$, and S10-S11 chromosome pairs, which are always homozygous $(\mathrm{HH})$. 

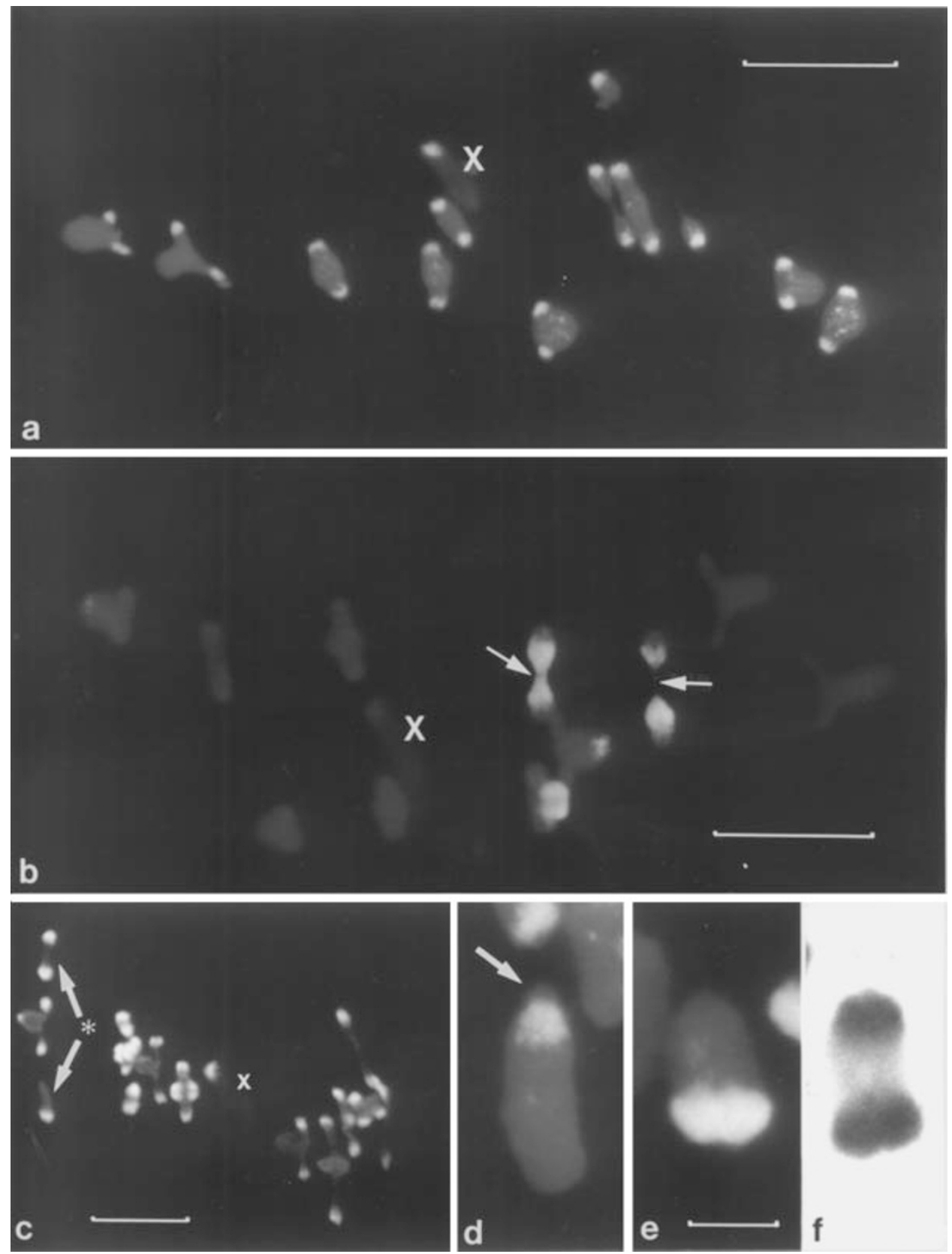

Fig. 2 Fluorescence in situ hybridization (a, b, d and e), DAPI staining (c) and C-banding (f) of Dociostaurus genei chromosomes. (a) Metaphase I hybridized with the DgT2 probe (centromeric heterochromatin), which shows that DgT2 is located solely in the centromeric region of each chromosome. Notice that, in every chromosome, a distal tip of euchromatin is observed beyond the labelled region. X, sex chromosome. (b) Metaphase I hybridized with the DgA3 probe (supernumerary heterochromatin), which shows the position of the extra segments. Two HH bivalents showing terminal associations are arrowed. The material that is positive to the hybridization seems to be involved in the maintenance of bivalent structure. X, sex chromosome. (c) Metaphase I stained with DAPI. Both the centromeric and supernumerary heterochromatin appear differentially stained. A BH bivalent (arrows) undergoes precocious reductional separation, so that one of the half-bivalents (bottom arrow) does not show any heterochromatin in the distal region. X, sex chromosome. (d) Selected mitotic chromosome hybridized with the DgT2 probe. A small tip of euchromatin (arrow) can be seen beyond the positively labelled region (compare with a and f). (e) Selected mitotic chromosome hybridized with the DgA3 probe. Notice that the extra segment occupies a truly terminal position, and no euchromatin can be seen beyond the segment. (f) Selected C-banded mitotic chromosome showing a large centromeric band and a distal supernumerary segment. No distal or proximal tips of euchromatin are discernible (compare with $\mathrm{d}$ and e). In a, b and c, bars represent $10 \mu \mathrm{m}$. In e, bar represents $2 \mu \mathrm{m}$; $\mathrm{d}$, e and $\mathrm{f}$ are at the same magnification. 
chromatic regions represent chiasmata: recombination within constitutive heterochromatin (LatosBielenska \& Vogel, 1990) and pseudoterminalization (Jones, 1978; Jones \& Tease, 1984). Reductional separation in $\mathrm{BH}$ bivalents is impossible under both these models. However, in D. genei, we have observed just such chromosome segregation with both C-banding (Fig. 1d) and DAPI staining (Fig. 2c). Another possibility is that true terminal segments do not exist. In fact, there are examples (Santos \& Esteban, 1990) in which a distal tip of euchromatin, which is commonly undetectable by C-banding, was discernible beyond the position of an extra segment. In this study, we have used three distinct procedures that selectively reveal the supernumerary segments. C-banding, fluorochrome (DAPI) banding and FISH reliably locate the segments in a distal position of mitotic chromosomes (Fig. 2d-f; Rodríguez Iñigo et al., 1996). However, at diplotene and metaphase I, some examples of end-to-end associations of $\mathrm{HH}$ bivalents (see Fig. 1a) do indeed reveal a region between both broad bands corresponding to each supernumerary segment, which might be composed of euchromatin. If this were the case, it should have been revealed by the staining techniques used here in mitotic chromosomes and half-bivalents at anaphase I, taking account of the appreciable size of that region. This view is reinforced by the results of FISH with the DgA3 and DgT2 probes, which are sequences that are highly represented in the supernumerary and procentric heterochromatin respectively. The DgT2 probe clearly reveals a small region beyond the pericentromeric heterochromatin in mitotic and meiotic chromosomes (Fig. 2a and d). This region is much more difficult to discern with C-banding or DAPI staining (compare Fig. 2a and d with Fig. 2c and f), and it is somewhat smaller than the presumed euchromatin region observable in some end-to-end contacts of $\mathrm{HH}$ bivalents (compare Figs 1a and 2a). Thus, although it remains a possibility that a very small portion of euchromatin, undetectable even with the highest resolution staining procedures for light microscopy, could be located beyond the segment and thus be involved in a chiasmate association, our results strongly suggest that in D. genei the supernumerary heterochromatin does indeed occur at distal positions. In fact, some bivalents at metaphase I show persistent terminal associations involving the material that is positively labelled by the DgA3 probe (Fig. $2 b$ ).

If supernumerary heterochromatin does occur distally, the terminal associations could confidently be considered to be truly achiasmate in $\mathrm{BH}$ and $\mathrm{HH}$ bivalents. Similar conclusions have been drawn from the application of distinct techniques in other grasshopper (John \& King, 1985) and mammal (Wada \& Imai, 1995) species. Santos \& Esteban (1990) used silver staining to show that, although most of the terminal associations can be considered to be chiasmate, nevertheless, achiasmate contacts between homologues also occurred. Likewise, Benavente et al. (1996) have shown by genomic in situ hybridization (GISH) that the frequency of terminal associations observed at metaphase I in wheat-rye hybrids is significantly higher than the number of recombinant half-bivalents scored at metaphase II. Accordingly, there is no correspondence between the frequency of bound arms held together by heterochromatic regions and chiasmata events. It should be pointed out that most of the rye chromosomes have distal blocks of heterochromatin.

Recently, Dernburg et al. (1996) have demonstrated the involvement of heterochromatic regions composed of particular repetitive DNA families in the achiasmate behaviour of the $\mathrm{X}$ and fourth chromosomes of Drosophila. Such a role for heterochromatic regions may also apply to other examples, including D. genei, in which achiasmate terminal associations have also been thought to occur (Hewitt, 1979). Moreover, the presence of achiasmate terminal associations, not only in $\mathrm{HH}$ bivalents but also in $\mathrm{BH}$ bivalents, indicates that the existence of such heterochromatic regions in both homologues is not essential for carrying out this function.

In summary, supernumerary segments in D. genei exert two distinct effects on chiasma formation: first, the number of chiasmata is reduced in complements with a higher content of extra heterochromatin; and secondly, chromosome segregation at anaphase I is not impaired by the occurrence of achiasmate terminal associations in which the segments are involved.

\section{Acknow ledgements}

This work has been supported by project 94/0212 awarded by the Fondo de Investigación Sanitaria (Spain) and project PM95/0038 awarded by the Dirección General de Enseñanza Superior (Spain).

\section{References}

BENAVENTE, E., FERNÁNDEZ-CALVÍN, B. AND ORELLANA, J. 1996. Relationship between the levels of wheat-rye metaphase I chromosomal pairing and recombination revealed by GISH. Chromosoma, 105, 92-96.

CAMACHO, J. P. M., VISERAS, E., NAVAS, J. AND CABRERO, J. 1984. C-heterochromatin content of supernumerary 
chromosome segments of grasshoppers: detection of a euchromatic extra segment. Heredity, 53, 165-175.

DE LA TORRE, J., LÓPEZ-FERNÁNDEZ, C., NICHOLS, R. AND GOSÁlVEZ, J. 1986. Heterochromatin readjusting chiasma distribution in two species of the genus Arcyptera: the effect among individuals and populations. Heredity, 56, 177-184.

DERnburG, A. F., SEDAT, J. W. AND HAWlEy, R. S. 1996. Direct evidence of a role for heterochromatin in meiotic chromosome segregation. Cell, 86, 135-146.

GARCÍA DE LA VEGA, C., GOSÁLVEZ, J., LÓPEZ-FERNÁNDEZ, C. AND RUfAS, J. S. 1986. Effects of different supernumerary segments on chiasma distribution of the polymorphic species Chorthippus jucundus (Orthoptera: Acrididae). Genetica, 69, 183-190.

Hewitt, G. M. 1979. Animal Cytogenetics. Orthoptera, Vol. 3. Insecta I. Gebrüder Borntraeger, Berlin.

JOHN, B. 1983. The role of chromosome change in the evolution of orthopteroid insects. In: Sharma, A. K. and Sharma. A. (eds) Chromosomes in the Evolution of Eukaryotic Groups I, pp. 1-110. CRC Press, Boca Raton, FL.

JOHN, B. AND KING, M. 1983. Population cytogenetics of Atractomorpha similis. I. C-band variation. Chromosoma, 88, 57-68.

JOHN, B. AND KING, M. 1985. Pseudoterminalisation, terminalisation and non-chiasmate modes of terminal association. Chromosoma, 92, 89-99.

JOHN, B., APPELS, R. AND CONTRERAs, N. 1986. Population cytogenetics of Atractomorpha similis. II. Molecular characterization of the distal C-bands polymorphisms. Chromosoma, 94, 45-58.

JONES, G. H. 1978. Giemsa C-banding of rye meiotic chromosomes and the nature of 'terminal' chiasmata. Chromosoma, 66, 45-57.

JONES, G. H. 1984. The control of chiasma distribution. In: Evans, C. W. and Dickinson, H. G. (eds), Controlling Events in Meiosis, pp. 293-320. The Company of Biologists Ltd, Cambridge.

JONES, G. H. 1987. Chiasmata. In: Moens, P. B. (ed.) Meiosis, pp. 213-244. Academic Press, Orlando, FL.
JONES, G. H. AND TEASE, c. 1984. Analysis of exchanges in differentially stained meiotic chromosomes of Locusta migratoria after BrdU substitution and FPG staining. IV. The nature of 'terminal associations'. Chromosoma, 89, 33-36.

LATOS-BIElEnSKA, A. AND VOGEL, w. 1990. Frequency and distribution of chiasmata in Syrian hamster spermatocytes studied by the BrdU antibody technique. Chromosoma, 99, 267-272.

LóPEZ-FERNÁNDEZ, C. AND gOSÁLVEZ, J. 1981. Differential staining of a heterochromatic zone in Arcyptera fusca (Orthoptera). Experientia, 37, 240.

RODRÍGUEZ-IÑIGO, E., BELLA, J. L. AND GARCÍA DE LA VEGA, C. 1993. Heterochromatin differentiation between two species of the genus Dociostaurus (Orthoptera: Acrididae). Heredity, 70, 458-465.

RODRÍGUEZ ÍNIIGO, E., FERNÁNDEZ-CALVÍN, B., CAPEL, J. AND GARCÍA DE LA VEGA, C. 1996. Equilocality and heterogeneity of constitutive heterochromatin: in situ localization of two families of highly repetitive DNA in Dociostaurus genei (Orthoptera). Heredity, 76, 70-76.

SANTOS, J. L. 1993. The effect of supernumerary segments on recombination in Euchorthippus pulvinatus (grasshopper): a comparative study between sexes and populations. Heredity, 70, 130-134.

SANTOS, J. L. AND ESTEBAN, M. R. 1990. On the nature of meiotic associations involving heterochromatic ends in grasshoppers. Genome, 33, 725-728.

SANTOS, J. L., DEL CERRO, A., FERnÁNDEZ, A. AND DÍEZ, M. 1993. The relationship between synapsis and chiasma distribution in grasshopper bivalents heterozygous for supernumerary segments. Heredity, 70, 135-141.

SUJA, J. A., ANTONIO, C., GARCía DE LA VEGA, C. AND RUFAS, J. S. 1994. Supernumerary chromosome segments and intrabivalent chiasma redistribution in Pyrgomorpha conica (Orthoptera). Heredity, 73, 1-10.

WADA, M. Y. AND IMAI, H. T. 1995. Theoretical analyses of chiasmata using a novel chiasma graph method applied to Chinese hamsters, mice and dog. Jap. J. Genet., 70, 233-265.

WOLF, K. w. 1994. How meiotic cells deal with non-exchange chromosomes. BioEssays, 16, 107-114. 